\title{
Variações composicionais de zircão em granitos anorogênicos proterozóicos do Cráton Amazônico: implicações metalogenéticas
}

\author{
Claudio Nery Lamarão ${ }^{1}$, Roberto Dall'Agnol', Gilvana Lima da Soledade ${ }^{2}$ \& \\ Joseanna dos Santos Silva²
}

\begin{abstract}
Resumo Zircões com teores elevados de Hf encontrados em rochas graníticas são típicos de granitos evoluídos e mineralizados a metais raros $(\mathrm{Sn}, \mathrm{Nb}, \mathrm{Ta}, \mathrm{W})$. Zircões de topázio granitos e granitos a metais raros mostram razões $\mathrm{Zr} / \mathrm{Hf}$ extremamente baixas, as quais podem ser interpretadas como uma assinatura herdada de fusões graníticas evoluídas ou, alternativamente, como o resultado de alteração hidrotermal de suas rochas hospedeiras por fluídos ricos em flúor. O presente trabalho é baseado em imagens de MEV e em análises semiquantitativas por EDS (Energy Dispersive Spectrometry). Os zircões estudados são de granitos estaníferos localizados nas províncias estaníferas do Sul do Pará, Pitinga e Rondônia e de granitos não mineralizados da Suíte Jamon, sudeste do Cráton Amazônico, e do granito pórfiro Santa Rosa, região de São Félix do Xingu. Os zircões dos granitos especializados são enriquecidos em Hf, Y, U e Th e mostram razões Zh/Hf mais baixas no sentido das fácies mais evoluídas desses corpos, sugerindo uma participação efetiva da diferenciação magmática nesse processo ou de intensa alteração hidrotermal nessas rochas. Os granitos não especializados mostram conteúdos mais baixos desses elementos e razões $\mathrm{Zr} / \mathrm{Hf}$ comparativamente mais elevadas. A assinatura geoquímica encontrada nos zircões dos granitos especializados indica que a composição do zircão pode ser um guia útil na avaliação do potencial metalogenético de granitos estaníferos. Uma avaliação preliminar do potencial estanífero de rochas granitóides pode ser baseada na variação composicional de zircões através de análises de MEV. Esta pode ser uma ferramenta importante em levantamentos voltados para a exploração mineral.
\end{abstract}

Palavras-chave: cráton amazônico, zircão, granitos estaníferos, prospecção, alteração hidrotermal.

\begin{abstract}
Compositional variation of zircons in paleoproterozoic anorogenic granites of the Amazonian Craton: metalogenetic implications. Hf-rich zircons in granitic rocks are typically associated with evolved, rare metals (Sn, Nb, Ta, W) specialized-granites. Zircons of topaz and rare-metal-bearing granites displays extremely low $\mathrm{Zr} / \mathrm{Hf}$ ratios that are interpreted as a magmatic signature inherited of evolved granitic melts or as the result of hydrothermal alteration of the host rocks by F-rich fluids. This study is based essentially on images of zircon crystals, obtained through a SEM, and on semi-quantitative Energy Dispersive Spectrometry (EDS) analyses. The analyzed zircon crystals are of tin-specialized granitoids of distinct tin provinces of the Amazonian craton: the South Pará, Pitinga, and Rondônia tin provinces. Zircon compositions of the A-type, not tin-mineralized granites of the Jamon Suite, southeastern of the Amazonian craton, and the Santa Rosa Granite, of the Xingu region are also presented for comparison. The zircon of the tin-specialized granites is characteristically enriched in $\mathrm{Hf}, \mathrm{Y}, \mathrm{U}$, and $\mathrm{Th}$ and displays lower $\mathrm{Zr} / \mathrm{Hf}$ ratios toward the more evolved facies, suggesting that magmatic differentiation was responsible for this particular feature. The zircons of the not mineralized granites show lower contents of these elements and comparatively high $\mathrm{Zr} / \mathrm{Hf}$ ratios. The characteristic geochemical signature in zircons of the Tin-specialized granites indicate that zircon composition can be a useful guide to evaluate the metallogenetic potential of tin-bearing granites. A preliminary evaluation of the potential for tin in evolved granites may be based on zircon compositional studies employing EDS semi-quantitative analyses obtained with a SEM. This can be an important tool for exploration surveys.
\end{abstract}

Keywords: Amazonian craton, zircon, tin-specialized granites, mineral exploration, hydrothermal alteration.

INTRODUÇÃO Zircões de rochas graníticas têm sido utilizados como indicadores petrogenéticos por vários autores (Murali et al. 1983, Uher et al. 1998, Pupin 1980, 2000, Wang et al. 2000, Belousova \& Griffin 2002, Kemp et al. 2004). Sua estabilidade química relativamente elevada, preservando-o de alterações $s u b$ solidus, somada à presença em sua estrutura cristalina de elementos traços característicos como $\mathrm{Hf}, \mathrm{Y}, \mathrm{Nb}, \mathrm{Th}$, $\mathrm{U}, \mathrm{Ca}, \mathrm{ETR}$ e P, tem permitido avanços importantes na caracterização de rochas fonte, na identificação de fracionamento de rochas ígneas e em estudos de proveniências (p.ex.Murali et al. 1983, Heaman et al. 1990, Hoskin \& Ireland 2000).

Zircões de rochas graníticas com teores muito

1 - Departamento Geoquímica e Petrologia, Centro de Geociências, UFPA, Belém (PA), Brasil. E-mail: lamarao@ufpa.br, robdal@ufpa.br 2 - Acadêmicos do Curso de Graduação em Geologia, PIBIC, PET, Centro de Geociências, UFPA, Belém (PA), Brasil. E-mail: soledade@ ufpa.br, joseanna@ufpa.br 
elevados de Hf são típicos de granitos evoluídos enriquecidos em metais raros ( $\mathrm{Sn}, \mathrm{Mo}, \mathrm{Ta}, \mathrm{W}, \mathrm{Li})$ e sua ocorrência seria indicativa da passagem de granitos para pegmatitos com metais raros (Kempe et al. 1997, Wang et al. 2000). Considerando-se que na maioria das rochas ígneas saturadas em sílica zircão é o principal mineral contendo Hf, a razão $\mathrm{Zr} / \mathrm{Hf}$ do cristal deve ser próxima da razão do magma original (Vlasov 1966, apud Pupin 2000). Análises em cristais de zircão obtidas em granitos com topázio e metais raros (Wang et al. 2000) mostraram razões $\mathrm{Zr} / \mathrm{Hf}$ extremamente baixas, interpretadas como uma assinatura primária de líquidos graníticos evoluídos ou, alternativamente, como tendo sido produzidas durante processos de albitização das rochas hospedeiras por fluídos ricos em F (Kempe et al. 2004).

Considerando as evidências de assinatura geoquímica característica em zircão de granitos especializados em metais raros, e sendo conhecidas diversas províncias graníticas proterozóicas mineralizadas em estanho no cráton Amazônico, fica evidente o interesse de desenvolver estudos composicionais em zircão de granitos representativos das principais províncias estaníferas do cráton. A avaliação da consistência dessa premissa é importante, pois sua confirmação pode introduzir o uso de novas ferramentas e dados geoquímicos na prospecção de corpos estaníferos, da mesma forma que sua negação indicaria a sua inadequação. Além disso, o estudo pode ter aplicação não apenas regional, mas também em outros domínios cratônicos do globo.

O presente trabalho envolve o estudo de cristais de zircão de corpos granitóides mineralizados com metais raros ( $\mathrm{Sn}, \mathrm{Nb}, \mathrm{Mo}, \mathrm{Ta}, \mathrm{W})$ que ocorrem na Província estanífera do sul do Pará (Dall'Agnol et al. 1993, CPRM/DNPM 1997, Teixeira et al, 1998, 2002), na Província estanífera de Pitinga, Amazonas (Borges 2002, Lenharo et al. 2002, Costi et al. 2000, 2002, 2005) e na Província estanífera de Rondônia, depósito de Bom Futuro (Bettencourt et al. 1997, Souza 2003), além de zircões provenientes de granitos da Suíte Jamon, região de Rio Maria, Província Mineral de Carajás (Oliveira 2001, Almeida 2005, Dall'Agnol et al. 2005). Todos os granitos mencionados foram estudados previamente em termos petrográficos, geoquímicos e geocronológicos. A tabela 1 apresenta informações petrográficas e geocronológicas dos corpos mencionados acima.

PROCEDIMENTOS ANALÍTICOS Os zircões selecionados foram analisados em Microscópio Eletrônico de Varredura, modelo LEO-1430, do Centro de Geociências da UFPA. As lâminas e seções polidas dos diferentes granitóides foram metalizadas com carbono para obtenção de imagens de elétrons retro-espalhados e análises semi-quantitativas por EDS (Energy Dispersive Spectrometry). As condições de análise foram: corrente do feixe $=90 \mu \mathrm{a}$, voltagem de aceleração constante $=$ $20 \mathrm{kv}$, distância de trabalho $=15 \mathrm{~mm}$, tempo de análise $=30 \mathrm{~s}$ com 4000 a $5000 \mathrm{c} / \mathrm{s}$ para cada análise. Foram analisados $\mathrm{O}, \mathrm{Si} \mathrm{Zr}, \mathrm{Hf}, \mathrm{Ce}, \mathrm{Nb}, \mathrm{Y}, \mathrm{Th}, \mathrm{U}, \mathrm{Ba}$ e Ca. As análises foram realizadas tanto nas bordas quanto no centro dos cristais, evitando-se, com a ajuda de imagens de elétrons retro-espalhados, regiões de fraturas, alterações e possíveis inclusões. Os resultados obtidos (Tab. 2) foram tratados em diagramas ternários e binários.

\section{CONTEXTO GEOLÓGICO DOS CORPOS GRA-} NITÓIDES ESTUDADOS O magmatismo anorogênico proterozóico do cráton Amazônico é representado por granitóides subalcalinos e alcalinos, com afinidades com granitos tipo-A (Loiselle \& Wones 1979), por vezes associados a rochas vulcânicas de composições intermediárias a félsicas, além de ocorrências subordinadas de rochas plutônicas máficas (Dall'Agnol et al. 1999, Teixeira et al. 2002). Os granitóides são interpretados como pertencentes à série de granitos rapakivi e podem hospedar, comumente em suas fácies mais evoluídas, mineralizações de Sn e outros metais raros (Bettencourt \& Dall'Agnol 1987, Horbe et al. 1991, Dall'Agnol et al. 1993, Costi et al. 2002, Teixeira et al. 2002).

Província estanífera do sul do Pará Na porção sulsudeste do Estado do Pará, parte da província mineral de Carajás, vários maciços graníticos e greisens mineralizados a metais raros ( $\mathrm{Sn}, \mathrm{Mo}, \mathrm{W}, \mathrm{Ta}, \mathrm{Nb}$ ) foram agrupados na suíte intrusiva Velho Guilherme (CPRM/ DNPM 1997, Teixeira et al. 2002). Esta engloba os granitos Antonio Vicente, Mocambo, Velho Guilherme, Benedita, Ubim-Norte, Ubim-Sul, Serra da Queimada e Rio Xingu, com idades de cristalização em torno de 1,88 Ga (Teixeira 1999, Teixeira et al. 2002; Pinho inédito).

Para este estudo foram selecionados quatro dos principais corpos graníticos mineralizados (Fig. 1A, Tab. 1): Antônio Vicente, Mocambo, Velho Guilherme e Serra da Queimada. Dados geoquímicos confirmam a natureza subalcalina a alcalina, o caráter metaluminoso a peraluminoso e uma assinatura intra-placa do tipo-A para esses corpos. Eles apresentam fácies afetadas por alterações pós-magmáticas e, localmente, greisens e rochas greisenizadas hospedeiras de cassiterita. (Teixeira et al. 2002).

Além desses corpos, foram estudados cristais de zircão de biotita sienogranitos pertencentes ao granito pórfiro Santa Rosa (Fig. 1A, Tab. 1), com idade de cristalização de 1,88 Ga (Paiva Júnior inédito) associado ao extenso vulcanismo do Grupo Uatumã. O granito pórfiro Santa Rosa aflora às proximidades de São Félix do Xingu e é tido como integrante da Suíte Intrusiva Velho Guilherme (Teixeira et al. 2002). Este corpo não possui registros de mineralizações associadas.

Província estanífera de Pitinga A região de Pitinga situa-se aproximadamente a $300 \mathrm{~km}$ ao norte da cidade de Manaus (Fig. 1B) e é dominada por rochas plutônicas graníticas e vulcânicas intermediárias a félsicas. $\mathrm{Na}$ área do depósito de Pitinga, riolitos, riodacitos e rochas piroclásticas pertencentes ao Grupo Iricoumé (ca. 1,88 Ga; Costi et al. 2000) são seccionadas pelos plutons Água Boa e Madeira, ambos estaníferos, com idades de cristalização em torno de 1,83-1,82 Ga e assinatura geoquímica de granito tipo-A (Costi 2000, Costi et al. 

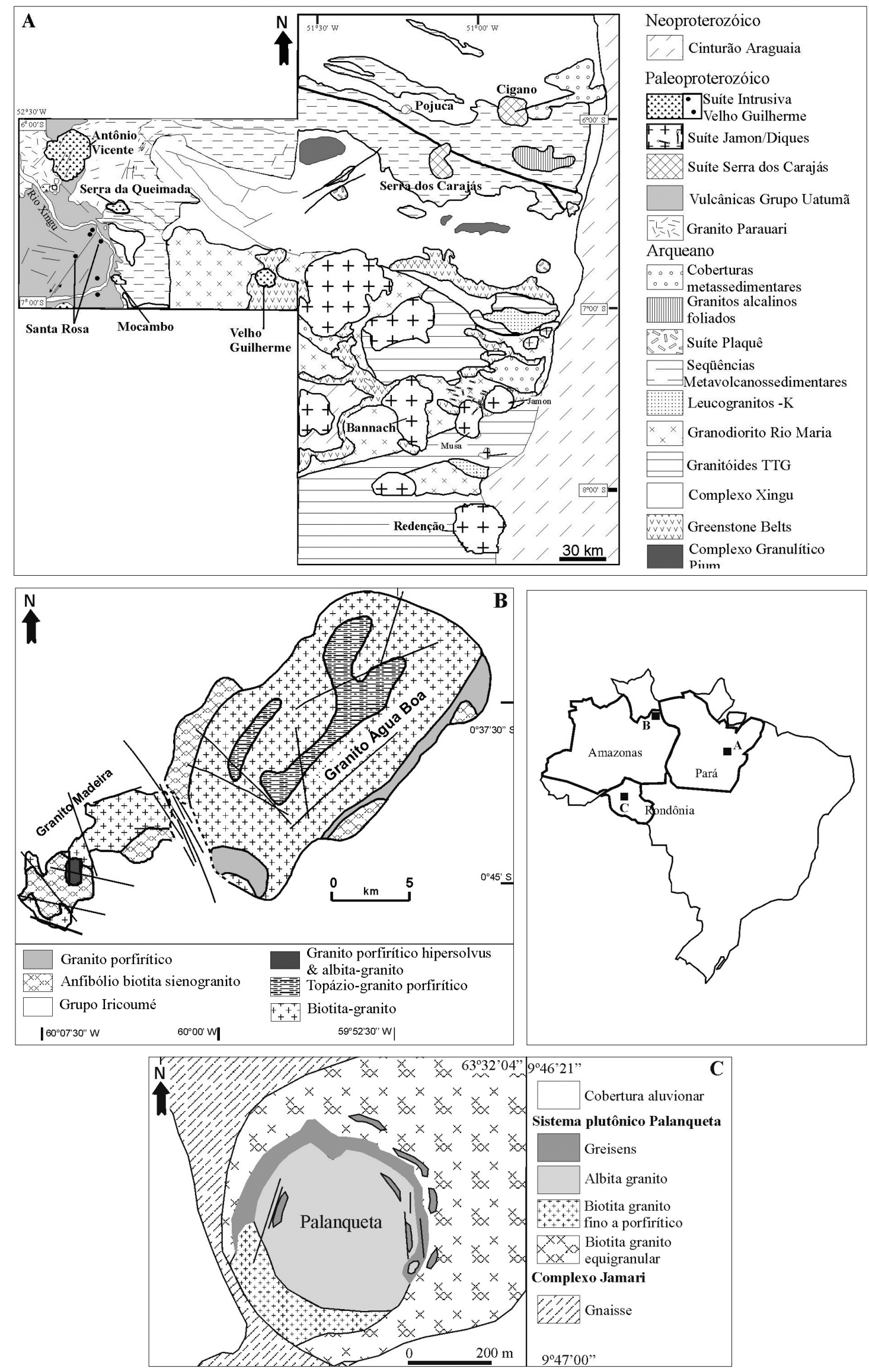

Figura 1 - Mapa de localizção dos corpos graniticos estudados. (A) Província estanífera do sul do Pará e região de Rio Maria (suite Jamon: modificado de Dall'Agno et al. 2005). (B) Provincia estanifera de Pitinga (modificado de Costi et al. 2002). (C) Depósito do Bom Futuro, província estanífera de Rondônia (Souza 2003, modificado). 
Tabela 1 - Dados petrográficos e geocronológicos dos granitóides estudados

\begin{tabular}{|c|c|c|c|c|c|c|}
\hline & Região & Tipo de Rocha & Afinidade & Idade (Ma) & Método & Ref. \\
\hline \multicolumn{7}{|c|}{ Província Estanífera do Sul do Pará } \\
\hline Antônio Vicente (\#) & Xingu (PA) & Sienogranito & Alcalina & $1867 \pm 4$ & $\mathrm{~Pb}-\mathrm{Pb} \mathrm{Zr}$ & 1 \\
\hline Mocambo (\#) & Xingu (PA) & $\begin{array}{c}\text { Sieno- } \\
\text { monzogranito }\end{array}$ & Alcalina & $1862 \pm 32$ (a) & $\mathrm{Pb}-\mathrm{Pb} \mathrm{Zr}$ & 1 \\
\hline Velho Guilherme (\#) & Xingu (PA) & Sienogranito & Alcalina & $1874 \pm 30$ & $\mathrm{~Pb}-\mathrm{Pb} \mathrm{Rt}$ & 2 \\
\hline Serra da Queimada (\#) & Xingu (PA) & $\begin{array}{c}\text { Sieno- } \\
\text { monzogranito }\end{array}$ & Alcalina & $1867 \pm 1$ & $\mathrm{~Pb}-\mathrm{Pb} \mathrm{Zr}$ & 3 \\
\hline Santa Rosa & Xingu (PA) & Sienogranito & Alcalina & $1888 \pm 2$ & $\mathrm{~Pb}-\mathrm{Pb} \mathrm{Zr}$ & 4 \\
\hline \multicolumn{7}{|c|}{ Província Estanífera de Pitinga } \\
\hline Água Boa (\#) & Pitinga (AM) & $\begin{array}{l}\text { Álcali-feldspato } \\
\text { granito }\end{array}$ & Alcalina & $1798 \pm 10$ & $\mathrm{U}-\mathrm{Pb} \mathrm{Zr}$ & 5 \\
\hline \multicolumn{7}{|c|}{ Província Estanífera de Rondônia } \\
\hline Bom Futuro (\#) & $\begin{array}{l}\text { Palanqueta } \\
\text { (RO) }\end{array}$ & Albita granito & Alcalina & $997 \pm 48$ & $\begin{array}{l}\mathrm{U}-\mathrm{Pb} \\
\mathrm{Mz}{ }^{*}\end{array}$ & 6 \\
\hline \multicolumn{7}{|l|}{ Região de Rio Maria } \\
\hline Redenção & $\begin{array}{l}\text { Rio Maria } \\
\quad \text { (PA) }\end{array}$ & Monzogranito & Subalcalina & $1870 \pm 68$ & $\mathrm{~Pb}-\mathrm{Pb} \mathrm{Rt}$ & 7 \\
\hline Bannach & $\begin{array}{l}\text { Rio Maria } \\
\text { (PA) }\end{array}$ & Monzogranito & Subalcalina & nd & nd & \\
\hline
\end{tabular}

1 = Teixeira et al. (2002); 2=Rodrigues et al. (1992), 3=Pinho (2005); 4=Paiva Junior (2004); 5=Costi et al (2000);

6=Souza (2003); 7=Barbosa et al. (1995)

$(\#)=$ Granitos mineralizados a Sn, Mo, W, Nb, Ta $\quad \mathrm{Zr}=$ Zircão $\quad \mathrm{Rt}=$ Rocha total $\quad \mathrm{Mz}=$ Monazita

* = idade do hidrotermalismo responsável pela geração dos greisens estaníferos nd=não datado

2000, 2002). Neste trabalho foram analisados cristais de zircão provenientes do pluton Água Boa, dos domínios mineralizados em estanho estudados por Borges (2002).

Província estanífera de Rondônia A província estanífera de Rondônia (Fig. 1C) compreende rochas metamórficas paleoproterozóicas a mesoproterozóicas, localmente cobertas por seqüências supracrustais não deformadas (Scandolara et al. 1999, Payolla et al. 2002). Vários episódios magmáticos, representados por sete suítes rapakivi com idades entre 1,60 e 0,97 Ga (Bettencourt et al. 1999), foram registrados na região. Essas suítes rapakivi são principalmente subalcalinas e metaluminosas a levemente peraluminosas, mostram assinatura geoquímica de granito tipo-A e caráter intraplacas (Bettencourt et al. 1997, 1999). O depósito estanífero de Bom Futuro localiza-se na região centro-oeste do estado de Rondônia e relaciona-se com um sistema vulcano-plutônico encaixado em gnaisses, anfibolitos e xistos do Complexo Jamari, parcialmente encoberto por sedimentos colúvio-aluvionares (Souza 2003). Foram estudados zircões provenientes do albita granito estanífero e do biotita granito equigranular encaixante do granito Palanqueta, situado nas proximidades do de- pósito de Bom Futuro propriamente dito.

Província mineral de Carajás, região de Rio Maria A província mineral de Carajás é formada em seu domínio sul pelo terreno granito-greenstone de Rio Maria (TGGRM), constituído por rochas mesoarqueanas, incluindo seqüências metavulcanossedimentares do tipo greenstone belt e granitóides variados, sobrepostos por coberturas sedimentares arqueanas (?) e cortadas por granitos anorogênicos paleoproterozóicos (Huhn et al. 1988, Souza et al. 1990, Althoff et al. 2000, Leite et al. 2004) e, 2) A bacia Carajás (Souza et al. 1996, Dall'Agnol et al. 2006) é composta dominantemente por rochas neoarqueanas, incluindo formações ferríferas bandadas e granitóides com idades entre 2,76 e 2,55 Ga (Machado et al. 1991). Os corpos anorogênicos presentes no TGGRM (Fig. 1A) foram agrupados na suíte Jamon (Dall'Agnol et al. 2005) que engloba os granitos Jamon, Musa, Marajoara, Bannach, Redenção, Gradaús, São João, Manda Saia e Seringa, todos com assinatura de granitos tipo-A da série rapakivi, e idades de cristalização de cerca de 1,88 Ga (Dall'Agnol et al. 1999, Oliveira 2001, Almeida 2005). Para esse estudo foram selecionados zircões de anfibólio-biotita-monzogranito, biotita monzogranito e leucogranitos dos cor- 
pos Redenção e Bannach.

RESULTADOS OBTIDOS A forma, textura interna e padrão de zoneamento dos cristais de zircão avaliados por imagens de elétrons retroespalhados, somados às análises químicas obtidas por EDS, mostram variações significativas.

\section{Província estanífera do sul do Pará}

GRANITO ANTONIO VICENTE No granito Antonio Vicente foram estudados zircões provenientes de biotita sienogranito (BSG), biotita sienogranito alterado (BSGA), biotita sienogranito intensamente alterado (BSGIA) e de rochas greisenizadas (denominações das fácies conforme Dall'Agnol et al. 1993 e Teixeira 1999). Os zircões do BSG são subédricos a anédricos, possuem fraco zoneamento, contêm raras inclusões de apatita e associam-se a cristais de magnetita+ilmenita em treliça (Fig. 2A). Seus teores de Hf variam de 1,88 a $2,27 \%$, com um valor médio de $2,2 \%$, e os de $\mathrm{Y}$ de $1,08 \%$ a $1,98 \%$, com média de $1,4 \%$. Suas razões $\mathrm{Zr} /$ Hf situam-se entre 26,75 e 39,05, com um valor médio de 33,1, a mais elevada dentre as quatro fácies estudadas. As concentrações médias de U, Th e Ca são inferiores a $0,3 \%$ (Tab. 2 ).

Nos BSGA e BSGIA os cristais de zircão são subédricos, zonados, contendo localmente finas inclusões de thorita e apatita. Manchas escuras, comumente acompanhando o zoneamento do cristal (Fig. 2B), têm teores mais elevados de Ca. Nos zircões do BSGA os conteúdos de Hf, U, Th e Ca são mais elevados e os de Y mais baixos do que nos zircões dos BSG (Tab. 2). O Hf varia de $1,92 \%$ a 7,12\%, com um conteúdo médio de 2,9\%, proporcionando uma razão $\mathrm{Zr} / \mathrm{Hf}$ média de 27,4. Nos BSGIA os zircões possuem teores de $\mathrm{Hf}$ e $\mathrm{Y}$ mais elevados do que os dos zircões das outras duas fácies, variando de $2,18 \%$ a $7,01 \%$ (média de $3,4 \%$ ) e de 0,92 a 10,48\% (média de 5,3\%), respectivamente. Os teores mais elevados de Hf nesses zircões geram razões $\mathrm{Zr} /$ Hf comparativamente mais baixas, com valor médio de 20,8 (Tab. 2).

Por fim, as rochas greisenizadas do granito Antonio Vicente mostram cristais de zircão anédricos, localmente subarredondados, fraturados, corroídos e raramente zonados, com teores médios de $\mathrm{Hf}$ e $\mathrm{Y}$ de $3,70 \%$ e $4,16 \%$, respectivamente, muito similares aos encontrados nos BSGIA (Tab. 2). Seus teores médios de $U(2,1 \%)$ e Th $(2,0 \%)$ são bem superiores àqueles encontrados nos zircões das rochas anteriores (Tab. 2).

GRANITO MOCAMBO Foram analisados zircões de rochas sienograníticas a monzograníticas porfiríticas (SMGP) e de rochas greisenizadas. No primeiro caso, os zircões são subédricos a anédricos, corroídos e com freqüentes inclusões de thorita (Fig. 2C). Análises realizadas nesses zircões revelaram valores médios de $\mathrm{Hf}$, Y e U de 4,5\%, 2,8\% e 1,6\%, respectivamente. A razão $\mathrm{Zr} / \mathrm{Hf}$ média encontrada foi de 16,9 (Tab. 2). Nas rochas greisenizadas, alguns cristais de zircão mostram bordas mais claras com teores de até $17,0 \%$ de Hf, e centros escuros com teores mais baixos (até $6,0 \% \mathrm{Hf}$ ), porém ainda comparativamente elevados. $\mathrm{O}$ valor médio de $\mathrm{Hf}$ encontrado nos zircões das rochas greisenizadas foi de $5,8 \%$, superior ao dos zircões dos SMGP (Tab. 2). Y e U são, em termos comparativos, levemente inferiores ( $2,2 \%$ e $1,2 \%$, respectivamente). A razão $\mathrm{Zr} / \mathrm{Hf}$ média encontrada nos zircões das rochas greisenizadas foi de 16,0 e os conteúdos de Th e Ca, próximos daqueles dos zircões das rochas porfiríticas (Tab. 2).

GRANITO VELHO GUILHERME No granito Velho Guilherme foram estudados cristais de zircão de biotita-sienogranito equigranular médio (BSGEm) e sienogranito heterogranular (SGH). Os zircões dessas rochas ocorrem como cristais dominantemente anédricos a subédricos, localmente subarredondados, fracamente zonados, corroídos, sendo comuns inclusões de thorita (Fig. 2D). Nos BSGEm os teores de Hf dos zircões analisados situam-se entre 1,76 e $6,51 \%$, com um valor médio de $3,2 \%$, enquanto os de Y variam de 1,10 a $12,5 \%$, com média de $4,0 \%$. Entretanto, são comuns cristais contendo zonas de borda mais claras com teores de $\mathrm{Y}$ mais elevados (até $11,5 \%$ de $\mathrm{Y}$ ). A razão $\mathrm{Zr}$ / Hf média dos zircões dessas rochas é de 22,2 (Tab. 2). Nos SGH, os cristais de zircão também mostram bordas mais claras, porém com teores de Y chegando a 19,7\%. $\mathrm{O}$ valor médio de $\mathrm{Y}$ encontrado para os cristais analisados foi de 7,6\% (Tab. 2). O Hf nessas rochas varia de 2,35 a $7,46 \%$, com uma média de $3,7 \%$. A razão $\mathrm{Zr} / \mathrm{Hf}$ média obtida nos zircões dos SGH foi de 16,5.

GRANITO SERRA DA QUEIMADA Os cristais de zircão analisados pertencem a rochas monzograníticas e sienograníticas. Eles são subédricos a anédricos, pouco zonados, geralmente corroídos e possuem freqüentes inclusões de thorita (Fig. 2E). A fluorita é uma fase comum nessas rochas. Os teores de Hf situam-se entre 2,68 e $10,7 \%$, com um valor médio de $5,5 \%$, proporcionando uma razão $\mathrm{Zr} / \mathrm{Hf}$ média de 12,93 , a mais baixa encontrada dentre os corpos da província estanífera do Sul do Pará. Os teores de Y variam de 0,47 a 7,68\%, com uma única análise apresentando valor de 14,47\% de Y. O conteúdo médio de Y nos zircões analisados, excluindo a análise com teor mais elevado, é de 2,7\%. U e Th apresentam concentrações médias de 1,7 e $0,7 \%$, respectivamente, que se superpõem às encontradas nos zircões dos outros corpos granitóides desta província, enquanto as de Ca são mais elevadas que aquelas dos zircões dos granitos Antonio Vicente e Mocambo, porém inferiores às encontradas nos zircões do granito Velho Guilherme (Tab. 2).

GRANITO PÓRFIRO SANTA ROSA Os biotita sienogranitos estudados possuem zircões euédricos a subédricos zonados (Fig. 2F) e empobrecidos em Hf, Y, U, Th e Ca em relação aos zircões dos granitos mineralizados. Os teores de Hf obtidos raramente alcançam 2,5\% em peso, proporcionando razões $\mathrm{Zr} / \mathrm{Hf}$ elevadas e com um valor médio de 38,8 , bem superior ao encontrado nos zircões do biotita sienogranito do pluton Antonio 
Variações composicionais de zircão em granitos anorogênicos proterozóicos do Cráton Amazônico: implicações metalogenéticas

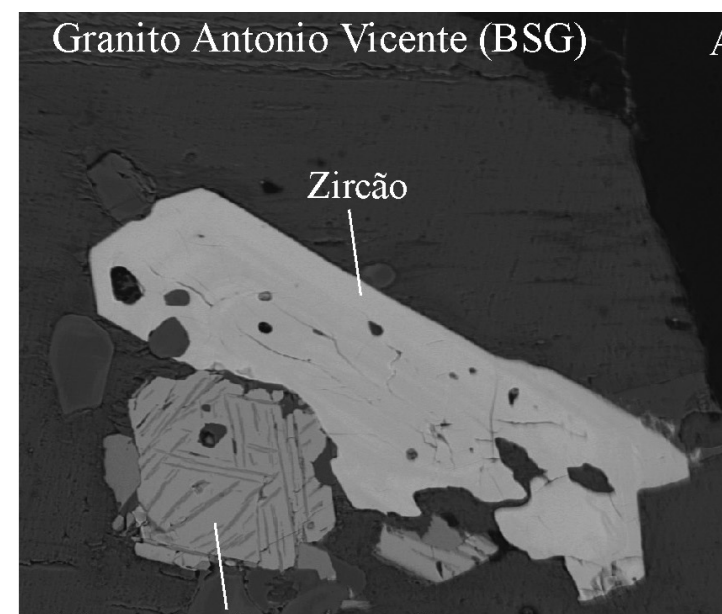

Magnetita+Ilmenita trellis
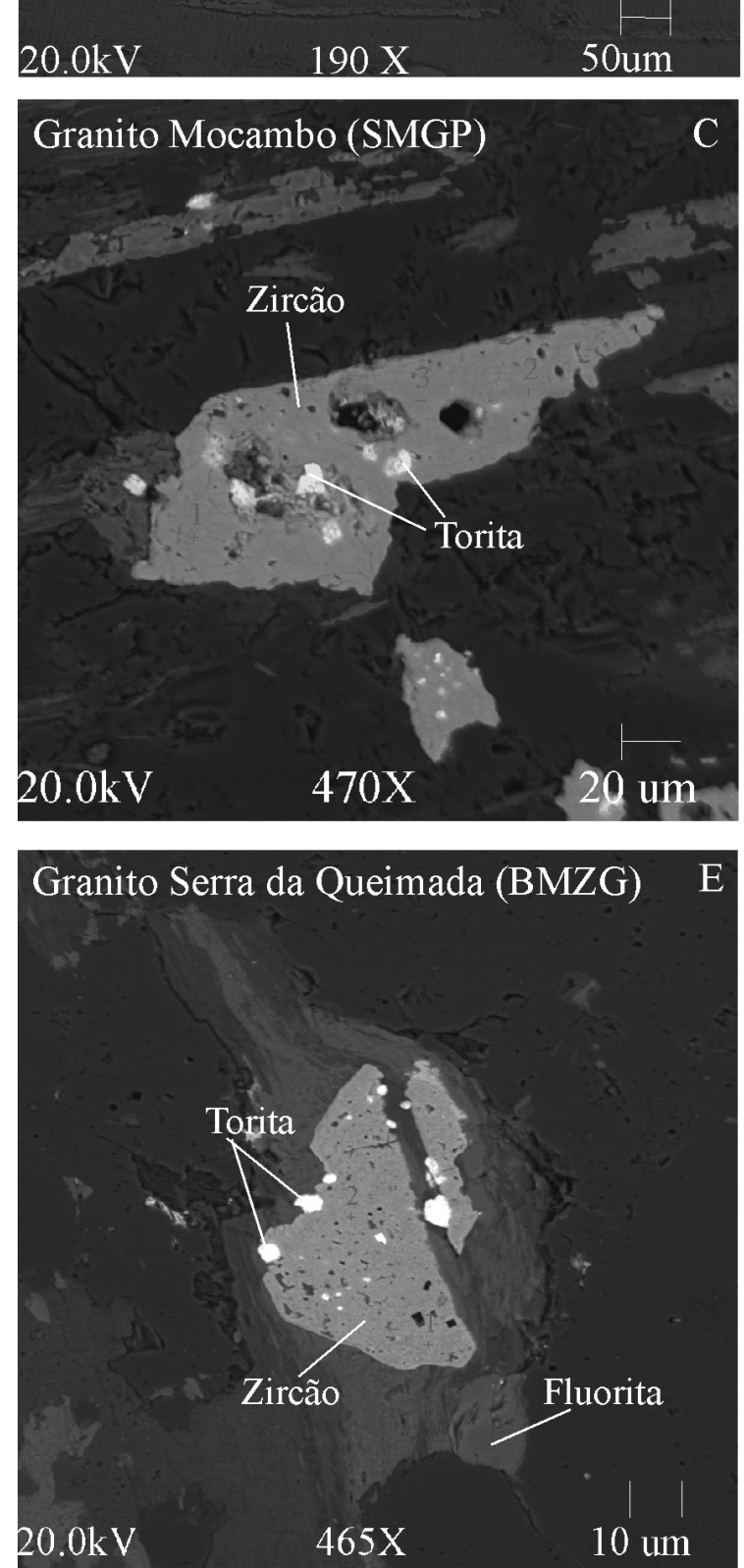
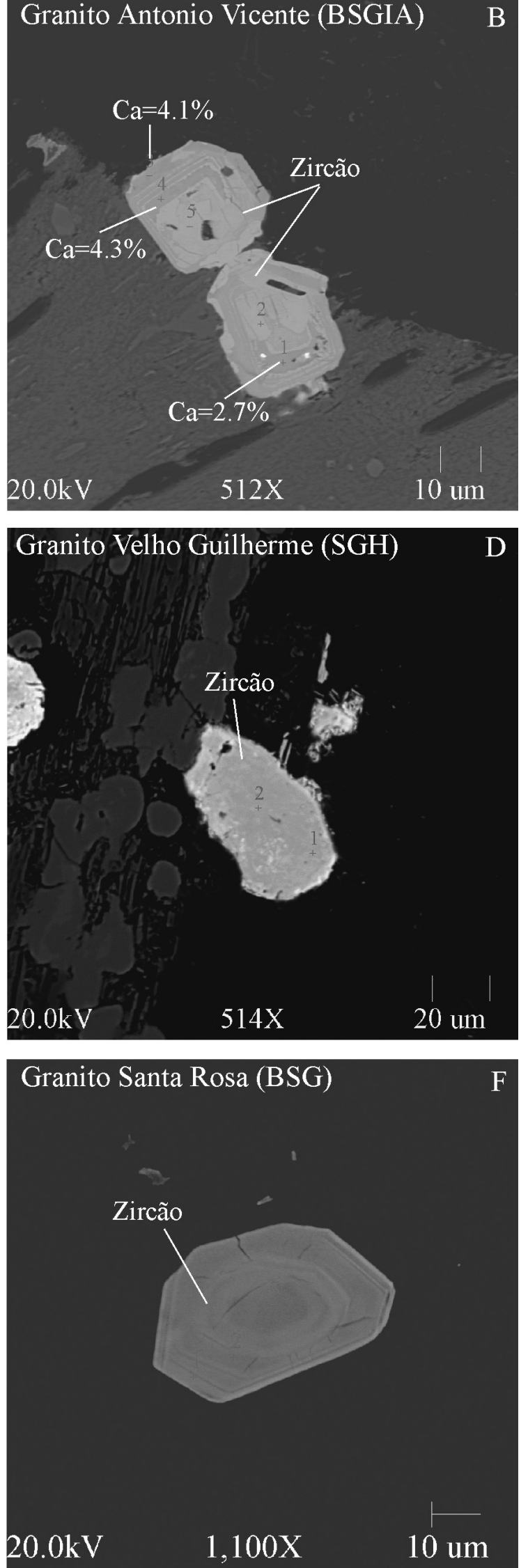

Figura 2 - Imagens de elétrons retro-espalhados. (A) Cristal subédrico de zircão contendo inclusões de apatita associado a magnetita e ilmentita trellis. (B) Cristais subédricos de zircão apresentando manchas escuras ricas em Ca. (C) Cristais anédricos de zircão, corroídos e com inclusões de torita. (D) Cristal de zircão anédrico, sub arredondado, mostrando borda e inclusões de torita. (E) Cristal de zircão anédrico e fortemente corroído, contendo inclusões de torita. (F) Cristal de zircão euédrico e zonado. 

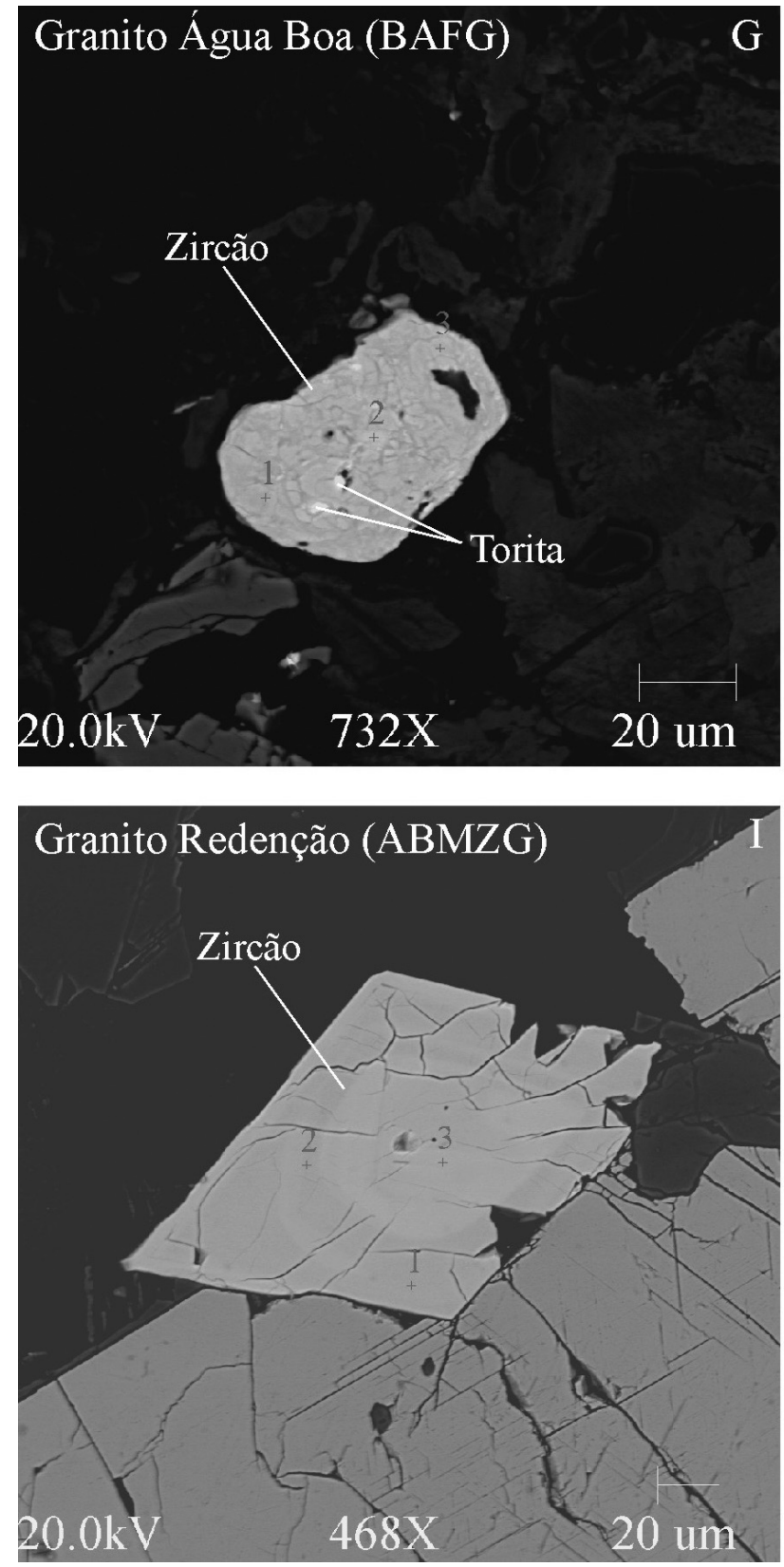
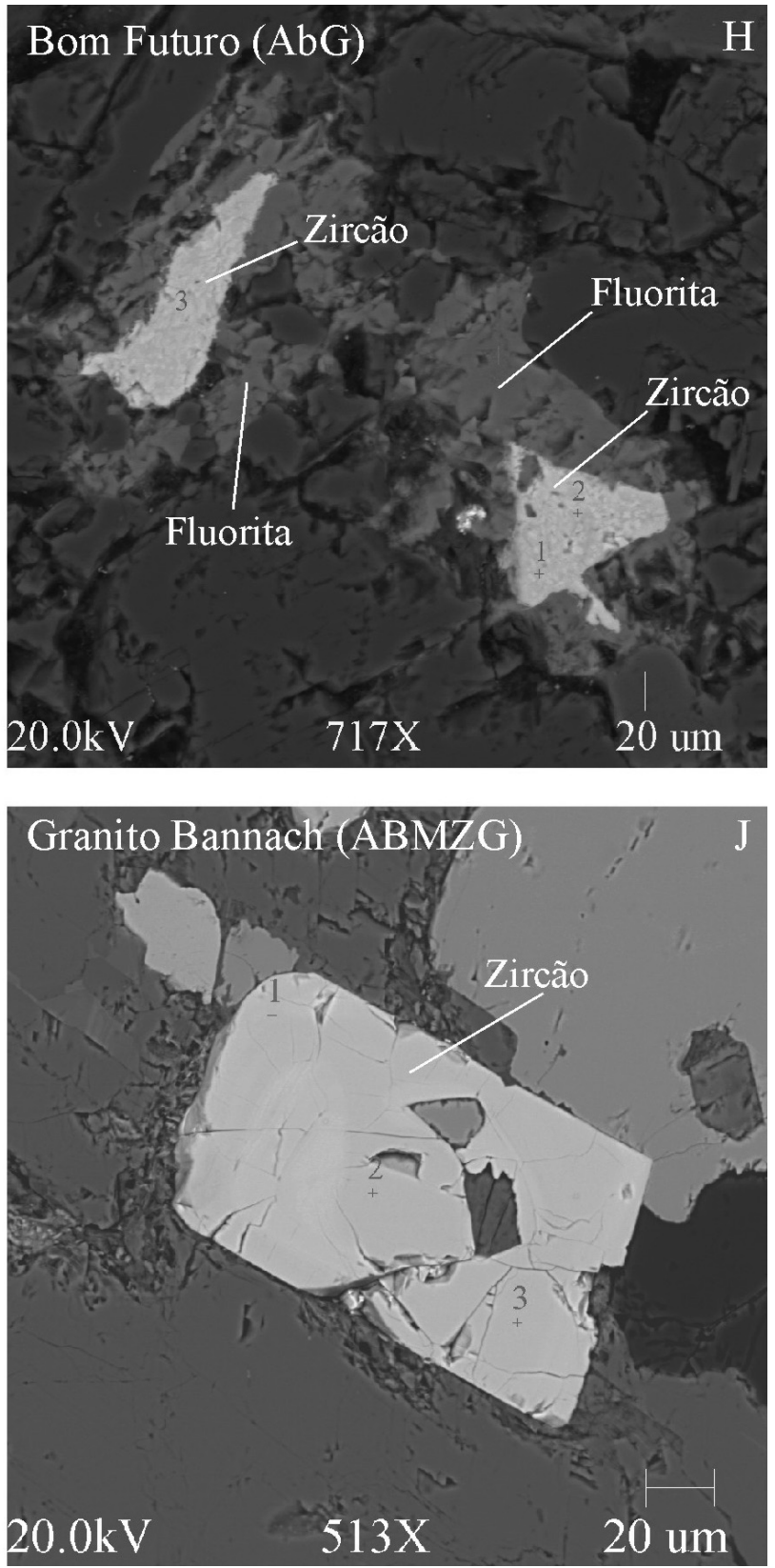

Figura 2 - Continuação. (G) Cristal subédrico a anédrico de zircão, corroído e fracamente zonado, contendo finas inclusões de torita. (H) Cristais anédricos de zircão, corroídos e fracamente zonados, inclusos em fluorita. (I) e (J) Cristais euédricos a subédricos de zircão mostrando fraco zoneamento e ausência de corrosão interna. BSG-biotita sienogranito; BSGIA-biotita sienogranito intensamente alterado; SMGP-sieno-monzogranito porfirítico; $S G H$-sienogranito heterogranular; BMZG-biotia monzogranito.

Vicente (Tab. 2).

\section{Província estanífera de Pitinga}

GRANITO ÁGUA BOA Foram analisados zircões de biotita-álcali-feldspato granito (BAFG) e topázio granito (TG) pertencentes ao pluton Água Boa. Os cristais estudados são anédricos a subédricos, corroídos, pouco zonados e raramente apresentam manchas internas escuras. Finos cristais de thorita estão presentes como inclusões (Fig. 2G).

Os teores de Hf dos zircões no BAFG variam de 1,98 a 7,55\% e no TG de 2,37 a 7,67\%, com valores médios de 3,9\% para ambos. Suas razões $\mathrm{Zr} / \mathrm{Hf}$ médias são também muito próximas (17,4 e 18,1, respectivamente). Por outro lado, os valores de Y são mais elevados nos zircões do BAFG $(1,48$ a 9,36\%, com um teor médio de $5,0 \%)$, do que no TG $(0,88$ e $8,75 \%$, com média de $2,7 \%$ ). O teor médio de $\mathrm{U}$ é maior que os encontrados nos zircões das demais rochas, aproximando-se apenas ao encontrado nas rochas greisenizadas do granito Antonio Vicente (Tab. 2). O conteúdo médio de Th dos zircões dos BAFG $(0,8 \%)$ se aproxima ao dos demais zircões analisados, porém é comparativamente mais elevado no TG $(2,8 \%)$. O Ca dos zircões dessas rochas apresenta teor médio de $1,1 \%$ nos BAFG e de $0,7 \%$ no TG. 
Variações composicionais de zircão em granitos anorogênicos proterozóicos do Cráton Amazônico: implicações metalogenéticas

Tabela 2 - Composições elementares médias de zircões dos corpos graníticos estudados obtidas por EDS (\% em peso)

\begin{tabular}{|c|c|c|c|c|c|c|c|}
\hline Pluton/Fácies/ $\mathrm{N}^{\circ}$ análises & $\mathrm{Zr} / \mathrm{Hf}$ & Hf & $\mathrm{Y}$ & $\mathrm{U}$ & $\mathrm{Th}$ & $\mathrm{Ca}$ & $\mathrm{Nb}$ \\
\hline \multicolumn{8}{|l|}{ Província Estanífera do Sul do Pará } \\
\hline \multicolumn{8}{|l|}{ Antônio Vicente (\#) } \\
\hline Biotita sienogranito (15) & 33,1 & 2,2 & 1,4 & 0,3 & 0,2 & 0,2 & 1,7 \\
\hline Biotita sienogranito alterado (21) & 27,4 & 2,9 & 1,2 & 0,6 & 0,3 & 1,2 & 1,5 \\
\hline Biotita sienogranito intensamente alterado (33) & 20,8 & 3,4 & 5,3 & 1,0 & 0,3 & 1,5 & 1,3 \\
\hline Rochas greisenizadas (26) & 19,8 & 3,7 & 4,2 & 2,1 & 2,0 & 1,0 & 1,7 \\
\hline \multicolumn{8}{|l|}{ Mocambo (\#) } \\
\hline Sienogranito monzogranito porfirítico (50) & 16,9 & 4,5 & 2,8 & 1,6 & 0,5 & 1,1 & 1,4 \\
\hline Rochas greisenizadas (24) & 16,0 & 5,8 & 2,2 & 1,2 & 0,7 & 1,2 & 1,1 \\
\hline \multicolumn{8}{|l|}{ Velho Guilherme $\quad(\#)$} \\
\hline Biotita sienogranito equigranular médio (28) & 22,2 & 3,2 & 4,0 & 1,2 & 0,5 & 2,5 & 1,7 \\
\hline Sienogranito heterogranular (52) & 16,5 & 3,7 & 7,6 & 1,7 & 0,9 & 4,0 & 0,9 \\
\hline \multicolumn{8}{|l|}{ Serra da Queimada (\#) } \\
\hline Biotita monzogranito-sienogranito (33) & 12,9 & 5,5 & 2,7 & 1,7 & 0,7 & 2,3 & 1,0 \\
\hline \multicolumn{8}{|l|}{ Santa Rosa } \\
\hline Biotita sienogranito (44) & 38,8 & 1,9 & 1,7 & 0,2 & 0,2 & 0,2 & 1,6 \\
\hline \multicolumn{8}{|l|}{ Província Estanífera de Pitinga } \\
\hline \multicolumn{8}{|l|}{ Água Boa (\#) } \\
\hline Biotita- álcali-feldspato granito (21) & 17,4 & 3,9 & 5,0 & 2,2 & 0,8 & 1,1 & 1,2 \\
\hline Topázio granito (38) & 18,1 & 3,9 & 2,7 & 2,1 & 2,8 & 0,7 & 1,1 \\
\hline \multicolumn{8}{|l|}{ Província Estanífera de Rondônia } \\
\hline \multicolumn{8}{|l|}{ Bom Futuro (\#) } \\
\hline Biotita granito equigranular (25) & 11,0 & 5,9 & 8,2 & 2,4 & 2,4 & 0,9 & 1,2 \\
\hline Albita granito (11) & 4,5 & 14,5 & 2,1 & 1,4 & 0,2 & 1,8 & 0,3 \\
\hline Região de Rio Maria & & & & & & & \\
\hline \multicolumn{8}{|l|}{ Redenção } \\
\hline Anfibólio-biotita monzogranito (46) & 36,4 & 2,0 & 1,7 & 0,3 & 0,3 & 0,2 & 1,40 \\
\hline Biotita monzogranito (23) & 30,6 & 2,5 & 1,3 & 0,3 & 0,2 & 0,2 & 2,0 \\
\hline Leucogranito (36) & 28,4 & 2,7 & 2,0 & 0,4 & 0,3 & 0,4 & 1,6 \\
\hline \multicolumn{8}{|l|}{ Bannach } \\
\hline Anfibólio-biotita monzogranito (36) & 34,5 & 2,1 & 1,9 & 0,3 & 0,2 & 0,7 & 1,5 \\
\hline Biotita monzogranito (48) & 30,6 & 2,5 & 1,9 & 0,4 & 0,2 & 1,3 & 1,8 \\
\hline
\end{tabular}

(\#) = Granitos mineralizados a Sn, Mo, W, Nb, Ta

\section{Província estanífera de Rondônia}

GRANITO PALANQUETA DO DEPÓSITO DE BOM FUTURO Foram estudados zircões de biotita granito equigranular e albita granito do granito Palanqueta. Os cristais apresentam-se subédricos a anédricos, comu- mente corroídos e fracamente zonados (Fig. 2H). Semelhantemente aos outros corpos estaníferos, os teores de Hf dos zircões analisados aumentam no sentido das rochas mais evoluídas. Os zircões do biotita granito apresentam concentração média de Hf de 5,9\% e do al- 
bita granito de $14,5 \%$, a mais elevada dentre todos os zircões estudados. A razão $\mathrm{Zr} / \mathrm{Hf}$ média encontrada nos zircões dessas rochas foi de 11,0 e 4,5, respectivamente (Tab. 2). Os teores de $Y$, U e Th são mais elevados nos zircões do biotita granito e suas concentrações médias são, nesta ordem, de $8,2 \%, 2,4 \%$ e $2,4 \%$. No albita granito os teores médios de $\mathrm{Y}, \mathrm{U}$ e Th são de $2,1 \%, 1,4 \% \mathrm{e}$ $0,2 \%$, respectivamente, enquanto $\mathrm{Ca}$ e $\mathrm{Nb}$ apresentam valores médios coincidentes com aqueles encontrados em zircões dos outros corpos especializados (Tab. 2).

Província mineral de Carajás, região de Rio Maria GRANITOS REDENÇÃO E BANNACH Foram estudados zircões de anfibólio-biotita monzogranito, biotita monzogranito e leucogranitos pertencentes aos plútons Redenção e Bannach da suíte Jamon. Os cristais analisados são euédricos a subédricos, pouco zonados e com até $0,5 \mathrm{~mm}$ de comprimento (Fig.s 2I, J). As concentrações médias de Hf e Y desses zircões são comparativamente inferiores às dos zircões das rochas mineralizadas, aproximando-se daquelas encontradas no granito Santa Rosa. As baixas concentrações de Hf fornecem razões $\mathrm{Zr} / \mathrm{Hf}$ médias elevadas (36,4 para o granito Redenção e 34,5 para o Bannach) quando comparadas às encontradas nos zircões das rochas especializadas. $U$, Th e Ca apresentam baixas concentrações nesses zircões e se superpõem aos valores encontrados nos zircões do granito Santa Rosa (Tab. 2).

$\mathrm{O} \mathrm{Nb}$ não apresenta variações expressivas, nem entre os zircões das diferentes fácies de um mesmo granito, nem entre os zircões dos granitos especializados e os demais. Entretanto, os dados obtidos sugerem tendência ao decréscimo deste elemento nos zircões das rochas mais evoluídas ou mais transformadas. $\mathrm{O}$ valor mínimo é mostrado pelos zircões do albita-granito Palanqueta, depósito do Bom Futuro.

DISCUSSÃO E CONCLUSÕES Uher et al. (1998) e Wang et al. (2000) consideram que zircões com concentrações elevadas de $\mathrm{Hf}$ e baixas razões $\mathrm{Zr} / \mathrm{Hf}$ são reflexo de níveis extremos de fracionamento, típicos de pegmatitos ou granitos altamente evoluídos enriquecidos em metais raros. No entanto, Kempe et al. (2004) admitem que zircões ricos em $\mathrm{Hf}$ e com razões $\mathrm{Zr} / \mathrm{Hf}$ extremamente baixas não podem resultar de processos comuns de fracionamento magmático. Eles seriam resultantes de albitização de rochas graníticas evoluídas por fluídos ricos em $\mathrm{F}$ ou, alternativamente, traduziriam uma assinatura geoquímica da região fonte desses magmas graníticos evoluídos. A presença de manchas internas (patchy internal structures) em cristais de zircão, geralmente enriquecidas em Hf, Y, U, Th, Ca e Fe, foi interpretada como indicativa de alteração hidrotermal desse mineral (Pointer et al. 1988, Kempe et al. 1997, 2004, Uher et al. 1998).

Os zircões dos granitos especializados das províncias estanífera do sul do Pará, de Pitinga e do depósito de Bom Futuro em Rondônia são enriquecidos em Hf e Y, e mostram, claramente, um aumento nas concentrações, principalmente de Hf, e uma diminuição na razão $\mathrm{Zr} / \mathrm{Hf}$ no sentido das fácies mais evoluídas (Tab. 2), consistente com uma importante variação no grau de fracionamento entre as fácies. Entretanto, a presença comum de zircões anédricos, corroídos e contendo manchas internas escuras com teores elevados de $\mathrm{Hf}$ e Ca (Fig. 2B) seria indicativa da ação de processos hidrotermais afetando os zircões dessas rochas. Além disso, a ocorrência expressiva de minerais secundários como sericita-muscovita, topázio e fluorita, associados a processos de alteração como albitização e greisenização, demonstram a importância de efeitos hidrotermais superimpostos a essas rochas (Dall'Agnol et al. 1993, Teixeira 1999, Teixeira et al. 1998, 2002; Costi et al. 2000, 2002; Bettencourt et al. 1997; Souza 2003). Constatou-se, também, em inúmeras análises, que os teores mais elevados de Hf, e em alguns casos de Y e Th, estão presentes nas bordas dos cristais. O enriquecimento de Hf no sentido centro-borda de cristais de zircão foi reportado por Uher et al. (1998), Kempe et al. (1999) e Pupin (2000).

O granito Serra da Queimada, pouco conhecido do ponto de vista metalogenético, apresenta zircões com teores elevados de $\mathrm{Hf}$ e Y e a mais baixa razão $\mathrm{Zr} /$ Hf dentre os corpos que formam a suíte intrusiva Velho Guilherme, sugerindo ser igualmente especializado. Teores mais elevados de Ca foram encontrados nos zircões dos granitos Velho Guilherme e Serra da Queimada (Tab. 1), o que pode indicar uma atividade hidrotermal mais intensa nesses corpos (cf. Kempe et al. 1999).

Por outro lado, os granitos da suíte Jamon (Redenção e Bannach) e o granito Santa Rosa, incluído na Suíte Velho Guilherme, mostram zircões com altas razões $\mathrm{Zr} / \mathrm{Hf}$ e baixas concentrações de Hf, Y, U, Th e $\mathrm{Ca}$ (Tab. 2) quando comparados aos zircões das rochas estaníferas, indicando serem desprovidos desse tipo de mineralização. Isso é consistente com a ausência de mineralizações de estanho e com o fato de terem os granitos da suíte Jamon caráter oxidado (Dall'Agnol et al. 2005), o que é geralmente considerado como uma feição desfavorável para a geração de depósitos estaníferos (Ishihara 1981).

Como observado no diagrama Hf-Y-Nb (Fig. 3) os zircões dos granitos especializados deste estudo tendem a definir um trend paralelo ao lado Hf-Y, enquanto os demais, com teores semelhantes de $\mathrm{Nb}$ (Tab. 2), porém com conteúdos comparativamente menores de Hf e Y, ocupam a porção central do diagrama, porque os três elementos exibem valores próximos.

As concentrações elevadas de Hf encontradas nos zircões dos granitos especializados proporcionam baixas razões $\mathrm{Zr} / \mathrm{Hf}$, bem diferentes daquelas encontradas nos granitos não mineralizados. A figura 4 compara essas razões e separa as rochas estudadas em dois grupos distintos: o dos granitos especializados com baixas razões $\mathrm{Zr} / \mathrm{Hf}$ e o dos granitos não mineralizados com razões mais elevadas. Observa-se também, que os zircões do biotita sienogranito do granito Antonio Vicente possuem razões $\mathrm{Zr} / \mathrm{Hf}$ que se superpõem parcialmente com as menores razões encontradas nos zircões dos granitos estéreis. Tal fato pode indicar que mesmo o 
biotita sienogranito desse corpo guarda a assinatura de uma fonte especializada (cf. Kempe et al. 2004).

Além de Hf e Y, os zircões dos granitos especializados mostram comumente teores mais elevados de Th e U quando comparados aos zircões dos granitos não mineralizados (Tab. 2). O diagrama $\mathrm{Zr} / \mathrm{Hf} \mathrm{x}$ $\mathrm{Hf}+\mathrm{Y}+\mathrm{Th}+\mathrm{U}$ (Fig. 5) mostra claramente o enriquecimento desses elementos nos zircões dos granitos especializados, proporcionando sua nítida separação dos corpos estéreis para estanho.

Foi constatada a presença em granitos protero-

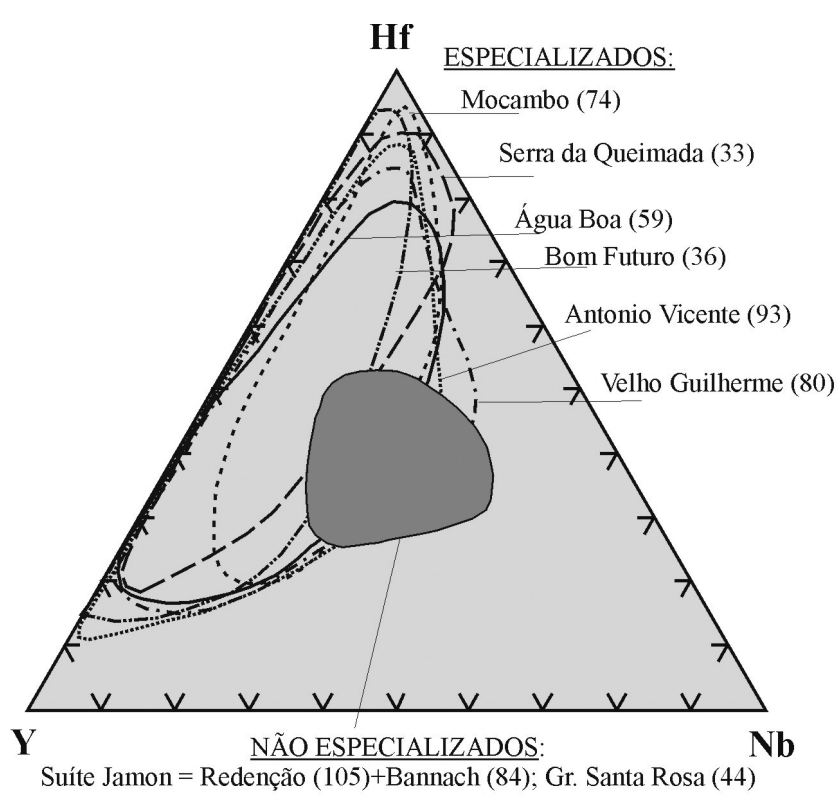

Figura 3 - Diagrama Hf-Y-Nb (\% em peso) mostrando os campos de variações composicionais dos zircões dos corpos graníticos estudados, com indicação do número de análises realizadas (entre parênteses).

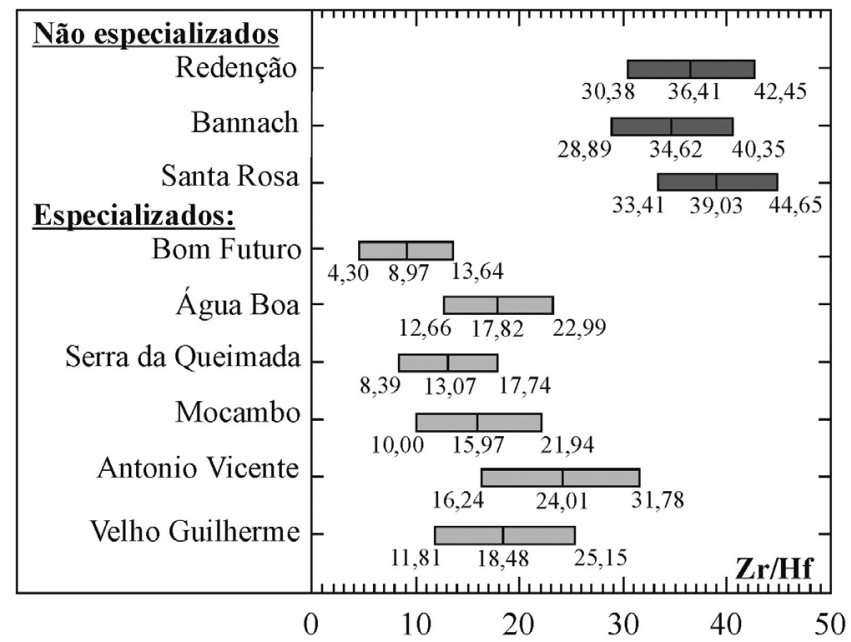

Figura 4 - Diagrama mostrando o valor mínimo, médio e máximo das razões $\mathrm{Zr} / \mathrm{H} f$ encontradas em zircões dos corpos graníticos estudados. zóicos especializados em Sn do cráton Amazônico de uma assinatura geoquímica característica no zircão, o qual se mostra enriquecido em Hf, Y, U, Th e Ca. Esta assinatura permite distingui-lo do zircão de granitos tipo-A proterozóicos não mineralizados em estanho, geralmente de caráter oxidado. Os resultados obtidos revelam que a composição do zircão pode ser utiliza-

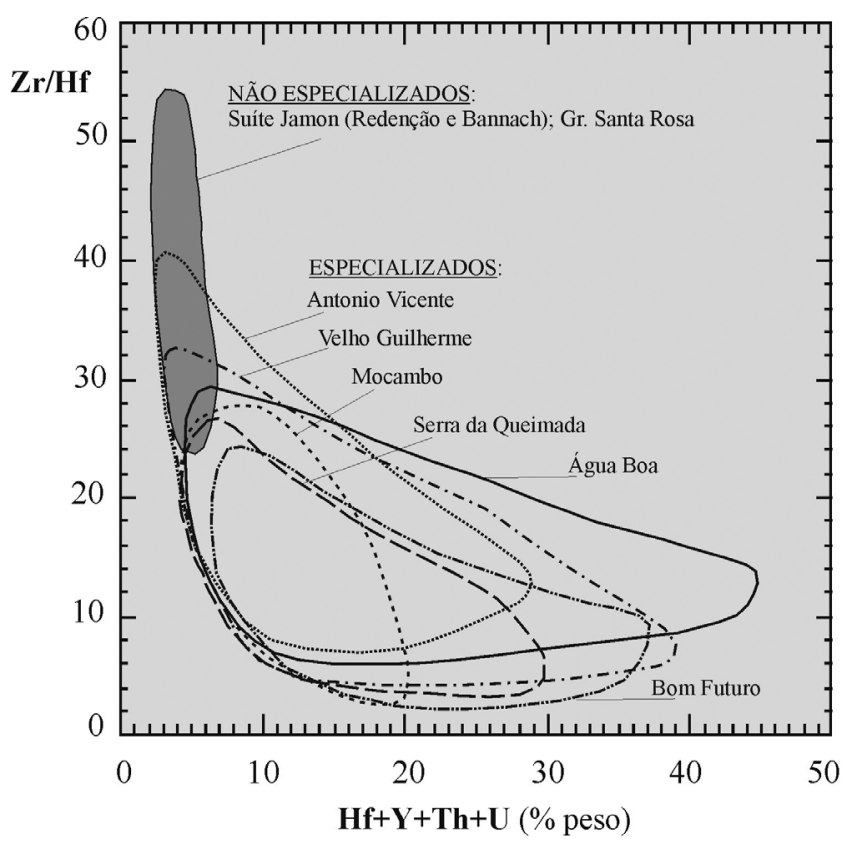

Figura 5 - Diagrama $\mathrm{Zr} / \mathrm{Hf}$ versus $\mathrm{Hf}+\mathrm{Y}+\mathrm{Th}+\mathrm{U}$ mostrando os campos de variações composicionais dos zircões dos corpos graníticos estudados.

da não apenas como traçador de regiões fonte e como indicador da natureza geoquímica de suas rochas ígneas hospedeiras, mas também na avaliação do potencial metalogenético das mesmas. Isto reforça o interesse em estudos composicionais de zircão no reconhecimento de zircões detríticos derivados de granitos especializados. Entretanto, a conclusão mais relevante deste estudo é a demonstração de que uma avaliação preliminar do potencial estanífero de granitos evoluídos pode ser baseada na variação composicional de zircão. Esta avaliação pode ser feita com base em análises semi-quantitativas (EDS) obtidas com o auxílio de MEV, de baixo custo e de obtenção relativamente rápida. Esta pode, portanto, ser uma ferramenta importante na exploração mineral, tanto nos estágios de levantamentos regionais preliminares, quanto em estudos detalhados visando a identificação de fácies especializadas mais promissoras.

Agradecimentos Aos colegas J.A.C. Almeida, R.M.K. Borges, H.T. Costi, D.C. Oliveira, M.L.E.S. Quadros, G.R.L. Feio, V.S. Souza, A.L. Paiva Júnior, S.C.C. Pinho, N.P. Teixeira (in memorian), ao IG da UFPA, ao CNPq (476075/03-3), a CAPES (Programa Nacional de Cooperação Acadêmica- PROCAD, Projeto 0096/05-9) e ao PRONEX/CNPq (Projeto 103-98 
- Processo 66.2103/1998-0) pelo apoio ao desenvolvimento da pesquisa. Este trabalho é uma contribuição para o projeto IGCP-510.

\section{Referências}

Almeida J.A.C. 2005. Geologia, petrografia e geoquímica do Granito anorogenico Bannach, Terreno Granito-Greenstone de Rio Maria, Pará. Dissertação de Mestrado, Centro de Geociências, Universidade Federal do Pará, $171 \mathrm{p}$.

Althoff F.J., Barbey P., Boullier A.M. 2000. 2.8-3.0 Ga plutonism and deformation in the SE Amazonian craton: the Archean granitoids of Marajoara (Carajás mineral province). Precambrian Res., 104: 187-206.

Barbosa A.A., Lafon J.M., Neves A.P., Vale A.G. 1995. Geocronologia $\mathrm{Rb}-\mathrm{Sr}$ e $\mathrm{Pb}-\mathrm{Pb}$ do Granito Redenção, SE do Pará: Implicações para a evolução do magmatismo proterozóico da região de Redenção. Bol. Mus. Par. Emílio Goeldi, sér. Ciências da Terra, 7:147-164.

Belousova E.A, \& Griffin W.L. 2002. Igneous zircon: trace element composition as an indicator of source rock type. Contrib. Mineral. Petrol., 143:602-622.

Bettencourt J.S., Leite Jr. W.B., Payolla B.L, Scandolara J.E., Muzzolon R. Vian J.A.J. 1997. The rapakivi granites of the Rondônia tin province, Northern Brazil. In: International Symposium on Granites and Associated Mineralizations, excursions guide, Salvador, p. 3-31.

Bettencourt J.S., Tosdal R.M., Leite Jr. W.B., Payolla B.L. 1999. Mesoproterozoic rapakivi granites of Rondonia tin province, southwestern border of the Amazonian craton, Brazil: I. reconnaissance $\mathrm{U}-\mathrm{Pb}$ geochronology and regional implications. Precambrian Res., 95: 41-67.

Bettencourt \& Dall'Agnol 1987. The Rondonian tin-bearing anorogenic granites and associated mineralizations. In: International Symposium on Granites and Associated Mineralizations (ISGAM), excursions guide, Salvador, Bahia, Brazil, p. 21-31.

Borges R.M.K. 2002. Greisens e epissienitos potássicos associados ao Granito Água boa, Pitinga (AM): um estudo dos processos hidrotermais geradores de mineralizações estaniferas. Tese de Doutoramento, Centro de Geociências, Universidade Federal do Pará, 348 p.

CPRM/DNPM 1997. São Félix do Xingu, Folha SB-22-Y-B. Brasília, Programa Levantamentos Geológicos Básicos do Brasil, MME/SMM.

Costi H.T. 2000. Petrologia de granitos alcalinos com alto flúor mineralizados em metais raros: o exemplo do albita-granito da mina Pitinga, Amazonas, Brasil. Tese de Doutoramento, Centro de Geociências, Universidade Federal do Pará, 345 p.

Costi H.T., Borges R.M.K., Dall'Agnol R. 2005. Depósitos de estanho da Mina Pitinga, Estado do Amazonas. In: O.J. Marini, E.T. Queiroz \& B.W. Ramos (eds.) Caracterização de depósitos minerais em distritos mineiros da Amazônia, Brasília, DNPM/CT MINERAL/ADIMB, capítulo VII, p. 391-475.

Costi H.T., Dall'Agnol R., Borges R.M.K., Minuzzi O.R.R., Teixeira J.T. 2002. Tin-bearing sodic episyenites asso- ciated with the Proterozoic, A-Type Água Boa Granite, Pitinga Mine, Amazonian Craton. Gondwana Res., 5(2): 435-451.

Costi H.T., Dall'Agnol R., Moura C.A.V. 2000. Geology and $\mathrm{Pb}-\mathrm{Pb}$ Geochronology of Paleoproterozoic volcanic and granitic rocks of Pitinga province, Amazonian craton, northern Brazil. Int. Geol. Rev., 42:832-849

Dall'Agnol R., Costi H.T., Leite A.A.S., Magalhães M.S., Teixeira N.P. 1999. Rapakivi granites from Brazil and adjacent areas. Precambrian Res., 95(1-2):3-39.

Dall'Agnol R., Oliveira M.A., Almeida J.A.C., Althoff F.J., Leite A.A.S., Oliveira D.C., Barros C.E.M. 2006. Archean and paleoproterozoic granitoids of the Carajás Metallogenic Province, eastern Amazonian Craton. In: Symposium on Magmatism, Crustal Evolution, and Metallogenesis of the Amazonian Craton, Field trips guide, p. 97-150.

Dall'Agnol R., Teixeira N.P., Magalhães M.S. 1993. Diagnostic features of the Tin-specialized anorogenic granites of the Eastern Amazonian Region. Anais Acad. Bras. Cienc., 65(1):33-50.

Dall'Agnol R., Teixeira N.P., Ramo O.T., Moura C.A.V., Macambira M.J.B., Oliveira D.C. 2005. Petrogenesis of the Paleoproterozoic, rapakivi, A-type granites of the Archean Carajás Metallogenic Province, Brazil. Lithos, 80:101-129.

Heaman L.M., Bowins R., Crocket J. 1990. The chemical composition of igneous zircon suites: Implications for geochemical tracer studies. Geochm. Cosmochem. Acta, 54:1597-1607.

Hoskin P.W.O. \& Ireland T.R. 2000. Rare earth element chemistry of zircon and its use as a provenance indicator. Geology, 28:627-630.

Horbe M.A., Horbe A.C., Costi H.T., Teixeira J.T. 1991. Geochemical characteristics of cryolite-tin-bearing granites from Pitinga Mine, northwestern Brazil - a review. Journal of Geochem. Explor., 40:227-249.

Huhn S.R.B., Santos A.B.S., Amaral A.F., Ledsham E.J., Gouvêa J.L., Martins L.P.B., Montalvão R.M.G., Costa V.G. 1988. O terreno "granite greenstone"da região de Rio Maria - Sul do Pará. In: SBG, Congresso Brasileiro de Geologia, 35, Belém, Anais, v.3, p. 1438-1452.

Ishihara S. 1981. The granitoid series and mineralization. Econ. Geol., 75:458-484

Kempe U., Gruner T., Renno A.D., Wolf D. 1997. Hf-rich zircon in rare-metal bearing granites: Magmatic or metasomatic origin? In: Papunen H. (eds.) Mineral Deposits: Research and Exploration. Rotterdam, Balkema, p. 643646.

Kempe U., Götze J., Dandar S., Habermann D. 1999. Magmatic and metassomatic processes during formation of the Nb-Zr-REE deposits Khaldzan Buregte and Tsakhir (Mongolian Altai): implications from a combined CL- 
SEM study. Mineral. Magazine, 63:165-177.

Kempe U., Gruner T., Renno A.D., Wolf D., René M. 2004. Discussion on Wang et al. (2000) "Chemistry of Hf-rich zircons from the Laoshan I- and A-type granites, Eastern China". Mineral. Magazine, 64:867-877.

Leite A.A.S., Dall'Agnol R., Macambira M.J.B., Althoff F.J. 2004. Geologia e geocronologia dos granitóides arqueanos da região de Xinguara (PA) e suas implicações na evolução do Terreno Granito-Greenstone de rio Maria. Revista Brasileira de Geociências, 34:447-458.

Lenharo S.L.R., Moura M.A., Botelho N.F. 2002. Petrogenetic and mineralization processes in Paleo- to Mesoproterozoic rapakivi granites: examples from Pitinga and Goiás, Brazil. Precambrian Res. 119: 277-299.

Loiselle M.C. \& Wones D.R. 1979. Characteristics and origin of anorogenic granites. Geol. Soc. Am. Abstr. Prog., 11:468.

Machado N., Lindenmayer Z.G., Krogh T.E., Lindenmayer D. 1991. U-Pb geochronology of Archean magmatism and basement reactivation in the Carajás area, Amazon shield, Brazil. Precambrian Res., 49:329-354.

Murali A.V., Parthasarathy R., Mahadevan T.M., Sankar Das M. 1983. Trace element characteristics, REE patterns and partition coefficients of zircons from different geological environments- a case study on Indian zircons. Geochim. Cosmochim Acta, 47:2047-2052.

Oliveira D.C. 2001. Geologia, geoquímica e petrologia magnética do granito paleoproterozóico Redenção, SE do Cráton Amazônico. Belém, Dissertação de Mestrado, Centro de Geociências, Universidade Federal do Pará, 207 p.

Payolla B.L., Bettencourt J.S., Kozuch M., Leite Jr. W.B., Fetter A.H., Van Schmus W.R. 2002. Geological evolution of the basement rocks in the east-central part of the Rondônia Tin Province, SW Amazonian craton, Brazil. $\mathrm{U}-\mathrm{Pb}$ and $\mathrm{Sm}-\mathrm{Nd}$ isotopic constraints. Precambrian Res., 119:141-169.

Pointer C.M., Ashworth J.R., Ixer R.A. 1988. The zirconthorite mineral group in metasomatized granite, Ririwai, Nigeria. 2. Zoning, alteration and exsolution in zircon. Mineralogy and Petrology, 39:21-37.

Pupin J.P. 1980. Zircon and granite petrology. Contributions to Mineralogy and Petrology, 73:207-220.

Pupin J.P. 2000. Granite genesis related to geodynamics from Hf-Y in zircon. Transactions of the Royal Society of Edinburgh Earth Sci., 91:245-256.

Rodrigues E., Lafon J.M., Scheller T. 1992. Geocronologia
$\mathrm{Pb}-\mathrm{Pb}$ da Província Mineral de Carajás: Primeiros resultados. In: SBG. Congr. Bras. Geol., 32, São Paulo, Anais, vol 1, p. 183-184.

Scandolara J.E., Rizzotto G.J., Bahia R.B.C., Quadros M.L.E.S., Amorim J.L., Dall'Igna L.G. 1999. Geologia e Recursos Minerais do estado de Rondônia: texto explicativo e mapa geológico na escala 1: 1.000.000. Brasília. Programa Levantamentos Geológicos do Brasil, CPRM.

Souza V.S. 2003. Evolução magmática e modelo metalogenético do sistema vulcano-plutônico estanífero Bom Futuro (RO). Tese de Doutoramento, Instituto de Geociências, Universidade de Brasília, $270 \mathrm{p}$.

Souza Z.S., Medeiros H., Althoff F.J., Dall'Agnol R. 1996. Geologia do terreno granito-greenstone Arqueano da região de Rio Maria, Sudeste do Pará. In: SBG, Congresso Brasileiro de Geologia, 36, Natal, Anais, v.6, p 29132928.

Teixeira N.P. 1999. Contribuição ao estudo das rochas granitóides e mineralizações associadas da Suite intrusiva Velho Guilherme, Província Estanifera do Sul do Pará. Tese de Doutoramento. Instituto de Geociências, Universidade de São Paulo, 508 p.

Teixeira N.P., Bettencourt J.S., Moura C.A.V., Dall'Agnol R. 1998. $\mathrm{Pb}-\mathrm{Pb}$ and $\mathrm{Sm}-\mathrm{Nd}$ constraints of the Velho Guilherme Intrusive suite and volcanic rocks of the Uatumã Group, south-southeastern Pará, Brazil. In: International field conference: Proterozoic granite systems of the Penokean Terrane in Wisconsin, field guide and proceeding volume. Madison, Wisc. Geol. Nat. Hist. Surv. Open File Rep. 1998-10, p. 178-180.

Teixeira N.P., Betencourt J.S., Moura C.A.V., Dall'Agnol R. \& Macambira E.M.B. 2002. Pb-Pb geochronology and $\mathrm{Sm}-\mathrm{Nd}$ isotopic composition of the Velho Guilherme Intrusive Suite and volcanic rocks of the Uatumã Group, south-southeast Pará - Brazil. Precambrian Res., 119(14):257-275.

Uher P., Breiter K., Klecka M., Pivec E. 1998. Zircon in highly evolved Hercynian Homolka Granite, Moldanubian Zone, Czech Republich: indicator of magma source and petrogenesis. Geologica Carpathica, 49(3),151-160. Wang R.C., Zhao G.T., Lu J.J., Chen X.M., Xu S.J., Wang D.Z. 2000. Chemistry of Hf-zircons from the Laoshan Iand A-type granites, Eastern China. Mineral. Magazine, 64:867-877.

Manuscrito AE 075-2006

Submetido em 12 de fevereiro de 2007 Aceito em 01 de dezembro de 2007 